\title{
STUDY OF BEARING CAPACITY OF VIBRATORY PILE APPLYING ACCELERATION RECORD
}

\author{
Kęstutis KELEVIŠIUSS ${ }^{\mathrm{a}}$, Linas GABRIELAITIS ${ }^{\mathrm{a}}$, Jonas AMŠIEJUS ${ }^{\mathrm{a}}$, \\ Arnoldas NORKUS ${ }^{\mathrm{a}}$, Zbigniew SIKORA ${ }^{\mathrm{b}}$ \\ ${ }^{a}$ Department of Geotechnical Engineering, Vilnius Gediminas Technical University, \\ Saulètekio al. 11, 10223 Vilnius, Lithuania \\ ${ }^{b}$ Department for Geotechnics, Geology \& Marine Engineering, Gdansk University of Technology, \\ G. Narutowicza St. No. 11/12, 80233 Gdańsk, Poland
}

Received 31 Dec 2012; accepted 04 Nov 2013

\begin{abstract}
The article focuses on the method for evaluation of ultimate bearing capacity for a vibratory pile having acceleration data recorded during the tests. The simulation vibratory pile installation test was performed in the testing stand. Accelerations were recorded on the top of the simulation vibratory pile during the test. The static test was performed for the installed pile. After the review of rheological models of the base, the Smith rheological model was chosen for determination of bearing capacity of the vibratory pile as this model, the rigidity of the final element of the spring is modelled as the finite rigidity of the base. Between the base of the modelled pile and the soil, a finite interface element is used. The interface element transfers only compression but it does not transfer tension to the base rheological model. The general stiffness of spring's finite element in the chosen rheological model is determined from experimental data of the static pile test. During the modelling, the damping coefficients and the ultimate displacements (responses) of the pile's shaft and base, to which the friction element became active, were determined so that the modelled pile accelerations and displacement (response) would coincide as much as possible with measured accelerations and their calculated response. The modelled and measured accelerations and responses showed high similarity.
\end{abstract}

Keywords: vibratory pile, rheological model, simulation, time step integration, ultimate bearing capacity.

Reference to this paper should be made as follows: Kelevišius, K.; Gabrielaitis, L.; Amšiejus, J.; Norkus, A.; Sikora, Z. 2013. Study of bearing capacity of vibratory pile applying acceleration record, Journal of Civil Engineering and Management 20(1): 142-148. http://dx.doi.org/10.3846/13923730.2013.870089

\section{Introduction}

The installation of piles using vibrodriveability techniques recently became an important issue in the geotechnical world. Customers expect that the installed vibratory piles would sustain bearing capacity for the design loads, while the contactors aim to the smallest difference of pile settlements (Gabrielaitis et al. 2013), which do not allow exceeding the limit values.

The bearing capacity of the installed pile (Adejumo, Boiko 2013) can be verified by applying one of the following methods: by applying the static pile test (ASTM D1143/D1143M-07 2007), dynamic pile test (ASTM D4945-08 2008) or the Standard Test Method for Axial Compressive Force Pulse Testing of Deep Foundations (rapid) (ASTM D7383-10 2010). The calculated bearing capacity on the vibratory pile is determined by applying mathematical simulation procedures for vibrodriving process (Middendorp, Verbeek 2012; Tsai et al. 2011; Sahajda 2011).

The results of the mathematical simulation procedures for vibro-driving process must as much as possible correspond with the result of pile installation characteristics obtained during the test (Žaržojus et al. 2013). The following rheological models can be used for the modelling: Smith (1960), Randolph and Simons (1986), Novak et al. (1978), Randolph and Worth (1978), Holeyman (1985), Nguyen (1988), El-Naggar and Novak (1994), Deeks and Randolph (1995), Michaelides et al. (1998a, b).

At present, it is possible to determine the bearing capacity of vibratory pile using, e.g. the static, dynamic pile test (ASTM D4945-08 2008) or axial compressive force pulse test (ASTM D7383-10 2010) just after the vibratory pile is installed but not during the installation.

The aim of this paper is a study of a correlation between the recorded characteristics of a vibratory pile installation and the bearing capacity.

\section{Analysis}

The static pile bearing capacity test (Igoe et al. 2010; Adejumo 2013) is an expensive and time consuming procedure when compared with the dynamic method (O'Neill et al. 1990) or the axial compressive force pulse test 
(Shooshpasha et al. 2013). To perform the static test, one should install a costly axial load anchoring system of the tested pile or bring the ballast with mass or total force of reaction system larger than bearing capacity of the pile. Additionally, one should use relevant beam and hydraulic jacks. The dynamic and axial compressive force pulse pile test methods are rather accurate and reliable. They do not require expensive equipment as for the static pile bearing capacity test. The duration of the dynamic and axial compressive force pulse test is much shorter compared with the static test. Due to the fact that the dynamic and axial compressive force pulse pile test methods are imperfect, a highly skilled and qualified engineer is necessary to interpret the test results and reliably determine the bearing capacity of the pile. It is possible to determine the bearing capacity of the driven pile when blowing technique is used for the pile response analysis by applying the records of accelerations and loads.

One can emphasize that in the last decade, many mathematical models for investigations of vibratory piles were proposed.

The main vibratory pile base simulation, i.e. rheological models, are as follow (Smith 1960): lateral friction and reaction of the base and the pile consists of a linear damper connected in parallel with the plastic friction element and linear variable spring connected in series. The model's reaction force depends on the base at the pile's estimated point, the pile wave velocity and the pile ultimate displacement of the moment of the onset of the friction force. The damping force linearly depends on the pilewave velocity damping coefficient $C$ and the base characteristics. The base characteristics are evaluated by the damping coefficient, $J$. The spring force depends linearly on the base limit strength. The friction element starts to affect perfectly plastically when ultimate pile displacement during impact or shift $Q$ is achieved. The mismatches observed were between the Smith's (1960) model and the pile driving mechanics. The mismatch is in the damper, which is always connected to the element. It is active both in the absence and upon achieving the ultimate displacement. The model is not characterised by hysteresis, energy dissipation to the base further away from the pile, and the creep dampening. The rheological model of Smith (1960) is proportional to the static ultimate strength. It is estimated that energy dissipation is dependent on the base stiffness, rather than on the ultimate base strength.

The lateral friction reaction model of Randolph and Simons (1986) consists of two parts: the first part consists of a spring and damper connected in parallel (which model the energy dissipation in the base) connected in series with the second part - the plastic of friction element and a damper connected in parallel. The second part simulates the shear force applied to the pile surface and the first the base, located further away from the pile, which has reached its fully plastic state. The spring stiffness and the damper's damping coefficient of the first model is calculated using the Novak's et al. (1978) solutions. These solutions are the analytical expressions of the ground reactions of the closed form of the infinitely long vertically vibrated rigid pile. It is assumed that a thin base layer is affected. This solution is suitable only on the assumption that the base is resilient and the pile is vibrated constantly. Later, Randolph (2003) improved constants for obtaining solutions. The model does not consider the hysteresis and nonlinearity of the base behaviour.

Holeyman's (1985) lateral friction reaction model consists of the base creep, base energy dissipation damper and the elastic spring connected in parallel. The previously mentioned elements connected in parallel are connected in series with a friction element. The values of attenuation coefficients are calculated like in the Randolph's and Simons's (1986) method, the radius calculation method of energy emission in the pile base is taken from the Randolph's and Wroth's (1978). Holeymann's (1985) proposed lateral friction model is different from the Randolph's and Simonson's (1986) model in two aspects: 1) the base is creepy before the pile sliding in the base; and 2) the spring stiffness is only suitable under static conditions. Such spring stiffness was chosen because it is then possible to assimilate the base hysteresis.

Nguyen's (1988) rheological model consists of three elements connected in parallel: 1) the base creepiness damper; 2) the base energy dissipation damper, and; 3) the linear friction and linear spring elements connected in series. The values of the energy dissipation damper of the spring rigidity of the side friction reaction model and the base are calculated according to that method proposed by Randolph and Simons (1986). The base creep damper is evaluated knowing the damping ratio $\xi$, and the ultimate value of the friction element is equal to the static limit value of lateral friction. Nguyen (1988) argued that the factor $\xi$ must be increased in simulations of the base creep increase. He also said that when the spring reaction exceeds the strength of the frictional element, and when the compression force of the spring does not increase, the friction begins. For this reason, the base energy dissipation damper must disconnect. However, upon disconnecting the base energy dissipation damper, the energy emission begins to decline sharply over time. Side friction calculation theory states that the friction element should be used not only when connected in series with the spring, but also when connecting in parallel with the lateral friction model for the reaction, as Holeyman (1988), and Randolph and Simons (1986) did. To evaluate the non-linearity of the base, instead of $G_{\max }$ Nguyen (1988) uses the reduced (secondary) shear modulus, which depends on the stress levels.

Deeks and Randolph (1995) have improved the pile base reaction model according to the analogue of the Lysmer's model (1966). The improvement was carried out as follows: the model elements and their structures under the pile base were changed so that the solution is most suitable to the results measured in practice. It was found that the most accurate model is similar by its first and second terms to the lateral friction model of Randolph and Simons (1986).

El-Naggar and Novak (1994) improved the model of Randolph and Simons (1986) by adding the base hysteresis and non-linearity effects. They identified three distinct zones at the side of the pile: 1) thin shear layer in contact 
with the side of the pile; 2) inner zone, which is dominated by hysteresis attenuation and base plasticity; and 3) the outer zone, featuring the linear-based behaviour. Model parts 1) and 3) are the same as in Randolph and Simons (1986). Part of the model 2) non-linearity relates the stresses and strains. Part 2) is a model of Kondner (1963). This model takes into account all the advantages of Randolph and Simons (1986) and complements it with the base nonlinearity and hysteresis.

Michaelides et al. (1998a, b) proposed the lateral friction reaction model, which considers the non-linearity of behaviour and hysteresis attenuation for the calculations of vibratory piles. Its solution is derived from the Novak's et al. (1978) solution for horizontally propagated shear waves. It was assumed that the wave propagates inside a thin disk. The calculation equations is written when a pile in the centre of the disc. Michaelides et al. (1998a) assumed that the secondary shear modulus decreases and the hysteresis damping ratio increases with shear displacements, on the basis of Ishibashi and Zhang (1993). The analysis of Michaelides et al. (1998b) is performed by making two approaches: initial (test) values are used in the first approached and the final variable values in the second approach. This method of analysis can be used when the pile is moving at constant amplitudes, with harmonic vibrations.

Holeyman (1988) proposed the models of lateral friction and the reactions of the base under the pile in which that part of the base array, adjacent to the pile, is measured by analysing the pile driving displacements over time. The main advantages of this method of analysis are: 1) any stress-strain states can be analysed realistically, with the assessment of the non-linearity of the base array behaviour and damping hysteresis; 2) the solution is suitable for a very short interval analysis. The downside of the model is that the analysis requires greater computing resources than the aforementioned rheological models.

\section{Motivation of the selected rheological model}

Having analysed the rheological models available in the literature, it was determined that the Smith's (1960) rheological model is the best for modelling the base resistance of vibratory pile. It can be used to determine the limits $10^{\text {th }}$ of the base using the data updated during the dynamic pile testing. However, on trial, if another rheological model would be applied, then any determination of shear modulus and Poisson's ratio of soil by processing data of pile test records, is difficult to obtain, since the soil strength is very sensitive versus the soil properties.

\section{Description of the performed test}

A driving test of vibratory pile was performed in the laboratory. The parameters of the utilized vibratory hammer are as follow: the total eccentric weight was $3.88 \mathrm{~kg}$ and eccentricity of the eccentric weight was $0.029 \mathrm{~m}$; the common mass of vibratory hammer amounted to $67.7 \mathrm{~kg}$. The inserting pile without static surcharge was realized with the frequency of rotating mass equal to $20 \mathrm{~Hz}$; that of the piles loaded with $120 \mathrm{~kg}$ of surcharge with the frequency of rotating mass of $30 \mathrm{~Hz}$. The employed piles with closed end were of the diameter $0.107 \mathrm{~m}, 18.3 \mathrm{~kg}$ and $1.8 \mathrm{~m}$ length.

The main strength parameter of the sandy soil, i.e. the internal friction angle was 43 degrees, the CPT on the soil surface was $0.00 \mathrm{MPa}$. From soil surface up to $1.2 \mathrm{~m}$ in depth, cone resistance increased linearly to $7.0 \mathrm{MPa}$. At greater depths, the cone resistance remained the same.

\section{Preparation for the test}

The following procedures were carried out. The soil was liquefied using the hydrodynamic forces. Afterwards, below the water level, which was deeper than the liquefied soil surface, the soil was compacted by the deep vibrator. The additional CPT penetration was performed at the place of pile test. The testing pile was equipped by the vibratory hammer at the testing mount, which allowed the vertical displacements only.

The accelerations were measured at the pile top with frequency of 2250 records per second. The pile without surcharge was penetrated by vibration up to $80 \mathrm{~cm}$ in depth. The test was continued with $120 \mathrm{~kg}$ of surcharge and was stopped at $1.40 \mathrm{~m}$ depth.

After the pile installation, its static test was performed. Each pile was loaded step-by-step with $7 \mathrm{kN}$ loadincrement during its static test. The displacements of pile top were measured at 3 points outside the pile, i.e. at points located 120 degrees between each other.

The outputs of the measurements were the acceleration plots versus time. A typical record for the pile subjected to $20 \mathrm{~Hz}$ vibratory loading during the settlement process is given in Figure 1.

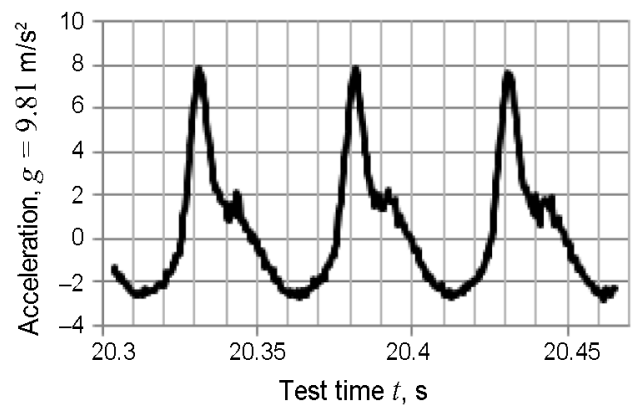

Fig. 1. Typical values of accelerations for the pile subjected to $20 \mathrm{~Hz}$ vibratory loading during the settlement process

Typical record for pile subjected to $20 \mathrm{~Hz}$ vibratory loads, in case when settlement process was stopped, is given in Figure 2.

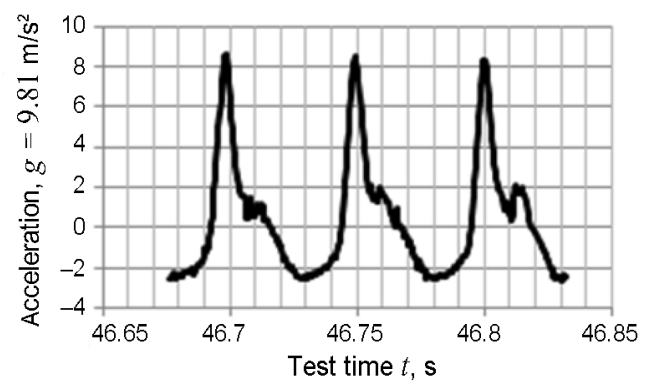

Fig. 2. Typical values of accelerations for the pile subjected to $20 \mathrm{~Hz}$ vibratory loads after the discontinuation of settlement 
Typical records for the pile, subjected to $30 \mathrm{~Hz}$ vibratory loadings and $120 \mathrm{~kg}$ static load during the settlement process is given in Figure 3.

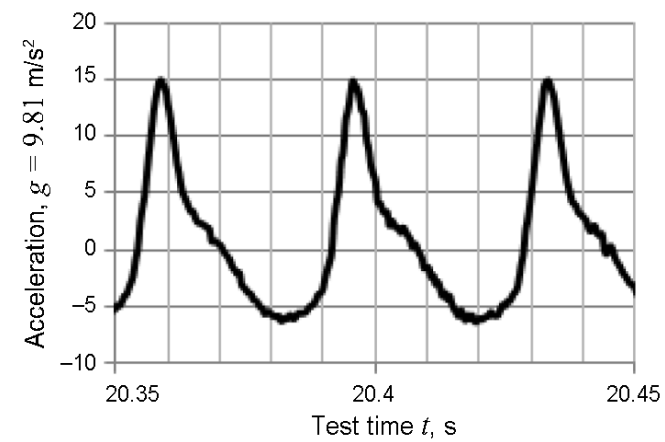

Fig. 3. Typical values of accelerations, for pile with settlements of $30 \mathrm{~Hz}$ loadings and $120 \mathrm{~kg}$ static load surcharge during the settlement process

Typical records for the pile subjected to $30 \mathrm{~Hz}$ vibratory loading and $120 \mathrm{~kg}$ static load surcharge when the settlement process stopped is given in Figure 4.

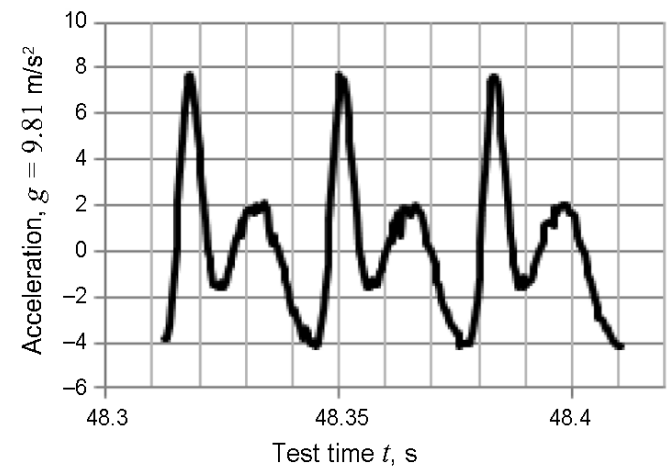

Fig. 4. Typical records for the pile subjected to $30 \mathrm{~Hz}$ vibratory loadings and $120 \mathrm{~kg}$ static load surcharge after settlement process was stopped

\section{Static pile test data}

The static test data is given in Figure 5. The determined pile bearing capacity was equal to $48.9 \mathrm{kN}$ corresponding to the $10 \%$ relative pile diameter settlement. The pile load-to-settlement ratio is presented in Figure 5.

Load $F, \mathrm{kN}$

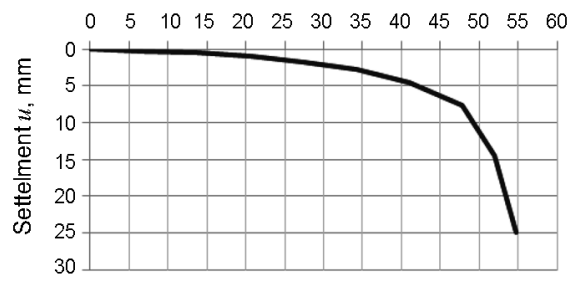

Fig. 5. Pile load versus settlement

\section{Mathematical modelling results}

The mathematical modelling of the installed vibratory pile was performed using the Smith's (1960) rheological model. The original computer program was developed applying the MATLAB ${ }^{\mathrm{TM}}$ software.

The parameters for calculation procedures have to be changed in order to receive the best agreement between the calculated accelerations of the vibratory response and the measured data. The data processing interface is given in Figure 6, the simulation result is given in Figure 7.

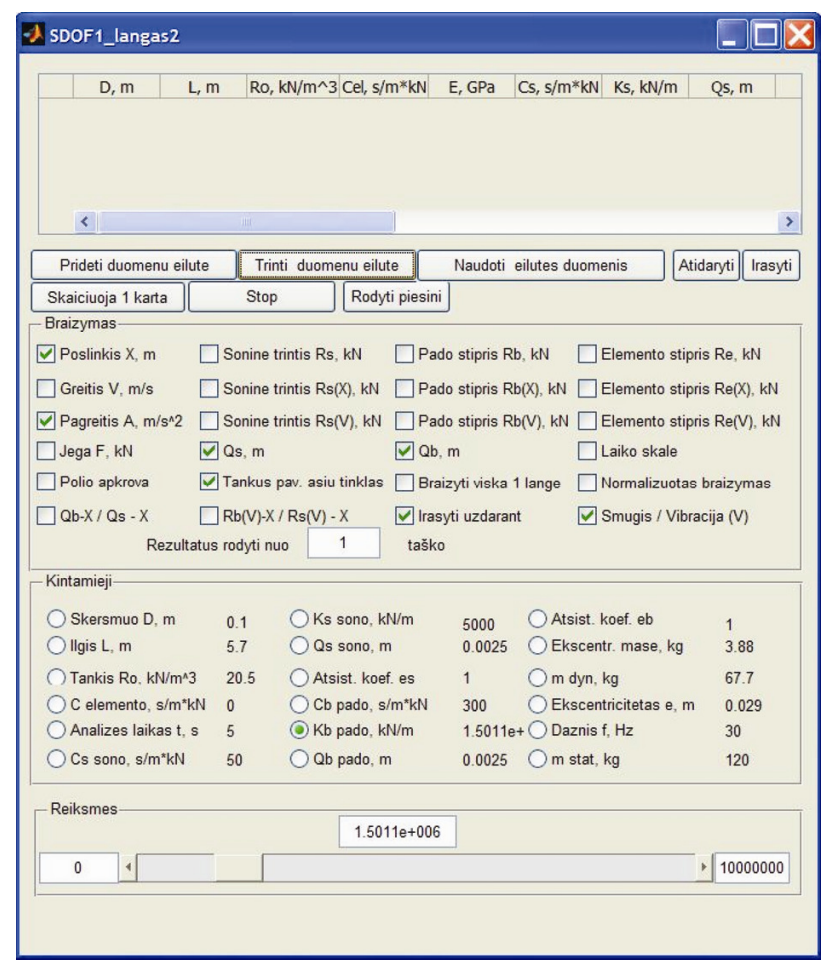

Fig. 6. Data processing interface

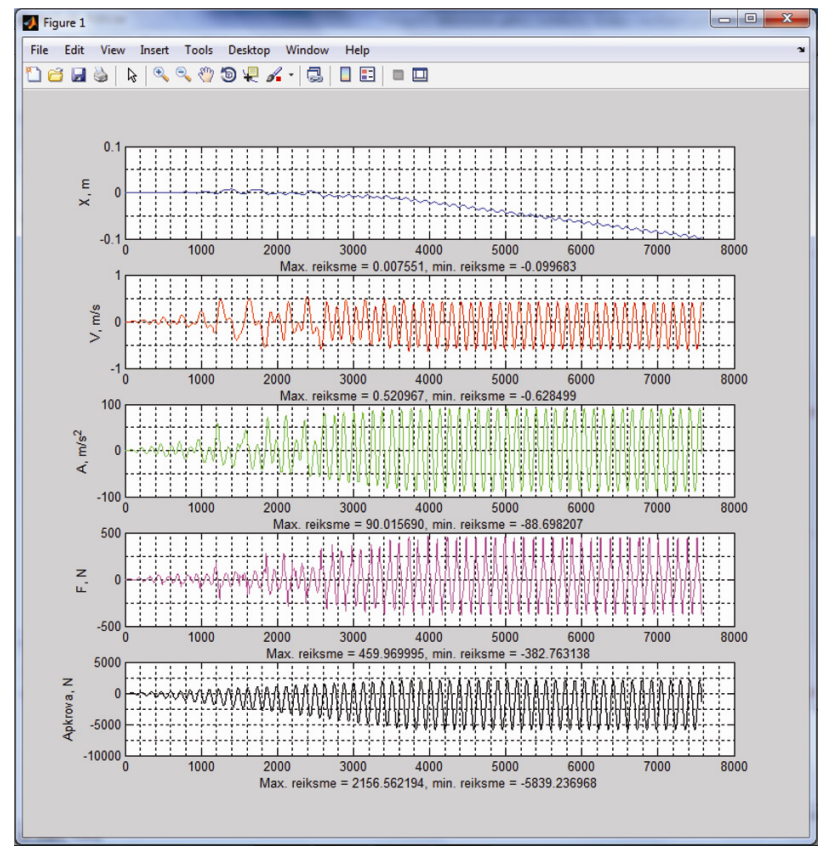

Fig. 7. Result plot window 
In the developed computer software, the Newmark (Gholampour, Ghassemieh 2012) integration method was utilized for the time integration. The computation procedure started from zero time point and continued by a constant increment of the design load magnitude to reach the calculated eccentric vibratory and surcharge force magnitudes. The scheme of the discrete model for vibratory pile after the Smith rheological model is given in Figure 8.

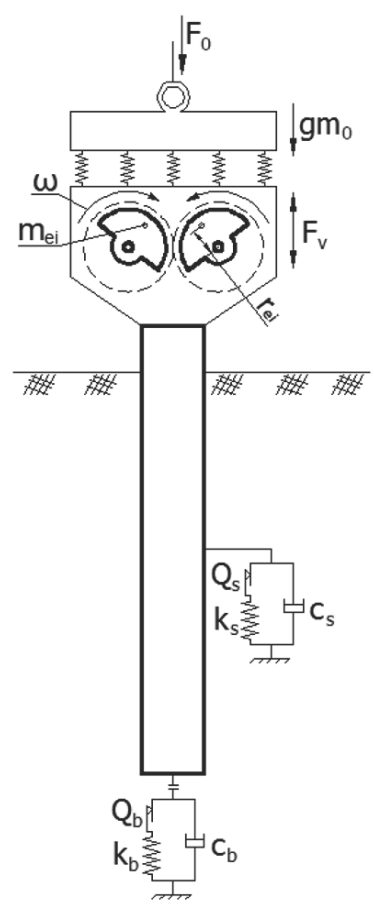

Fig. 8. Scheme of discrete model for vibratory pile
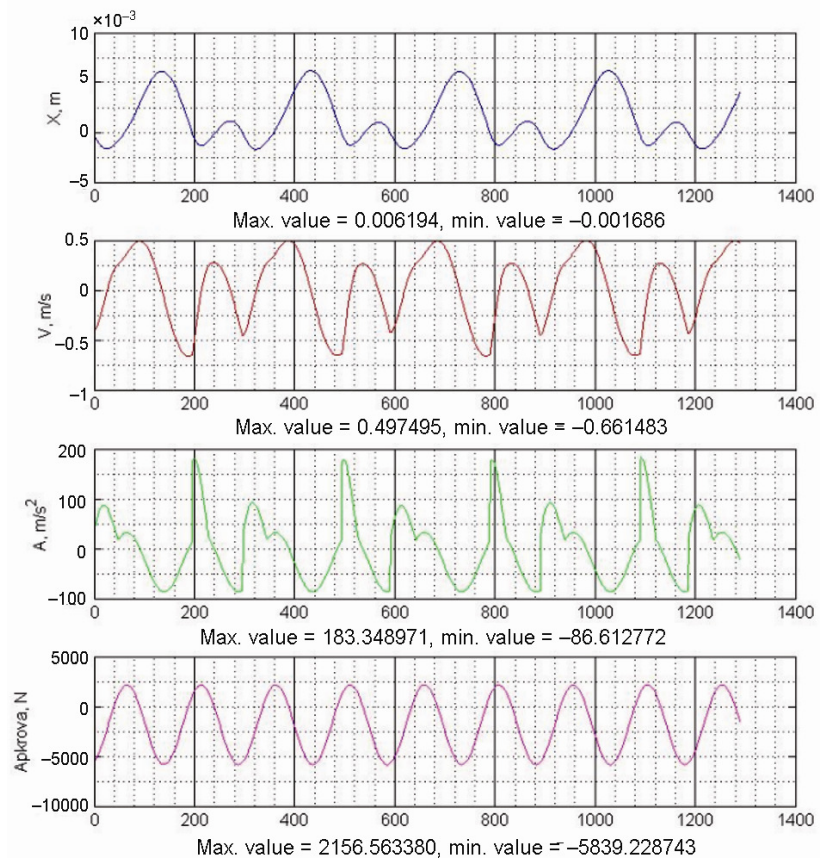

Fig. 9. Data processing interface of the pile
According to the proposal of Buehler et al. (2002), an interface element was introduced into the rheological model. The theoretical ultimate pile bearing capacity was chosen on the basis of the static test results. The soil ultimate strength in calculations was determined applying the static test results, assuming that the ultimate bearing capacity corresponds to $10 \%$ of relative pile diameter settlement. The determined pile ultimate bearing capacity was $48.9 \mathrm{kN}$. The soil stiffness modulus (computed) value was $4570 \mathrm{kN} / \mathrm{m}$. In the model, by assumption, the general stiffness of all spring-finite elements was analogous to the calculated pile-soil stiffness modulus. In Figure 9, the pile installation characteristics of the mathematical model results are given. The comparison of measured accelerations during the pile installation with the ones, obtained via mathematical modelling is given in Figure 10.

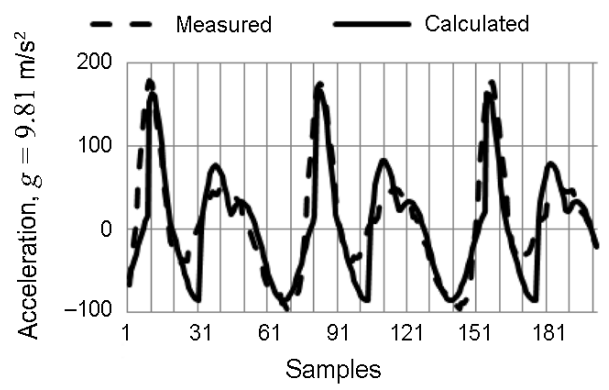

Fig. 10. Comparison of the measured accelerations during installation with the ones obtained via the mathematical modelling

It was found, that the pile-soil interaction damps at pile bottom. The reduction of shaft from $15 \mathrm{kN} \cdot \mathrm{s} / \mathrm{m}$ to $0.1 \mathrm{kN} \cdot \mathrm{s} / \mathrm{m}$ at the depth of (bottom pile at $1.4 \mathrm{~m}$ ) was identified. Therefore, the stiffness of the spring finite element was reduced from $4500 \mathrm{kN} / \mathrm{m}$ to $7 \mathrm{kN} / \mathrm{m}$, respectively. It yielded an activation of the friction at employed finite elements with $2.5 \mathrm{~mm}$ quake at the pile shaft and $10 \mathrm{~mm}$ quake at the pile base, respectively.

\section{Conclusions}

1. The computational results match the testmeasurements with sufficient accuracy.

2. Aiming to reduce discrepancy of accelerations curve (Fig. 10), one should add Randolph and Simons (1986) and subsequently developed rheological models that correspond to the vicinity soil of the analysed pile.

3. One should perform more tests of pile installation in order to evaluate the bearing capacity via mathematical modelling. The field experiments also have to be performed, and the obtained results should be compared with the results from stand tests.

\section{Acknowledgement}

The authors would like to express their gratitude for the equipment and infrastructure of Civil Engineering Research Centre of Vilnius Gediminas Technical University which was used for investigations. 


\section{References}

Adejumo, T. W. 2013. Settlement and deformation pattern of modeled wooden piles in clay, International Journal of Advanced Technology \& Engineering Research 3(3): 9499.

Adejumo, T. W.; Boiko, I. L. 2013. Effect of installation techniques on the allowable bearing capacity of modeled circular piles in layered soil, International Journal of Advanced Technology \& Engineering Research 2(8): 1536-1542.

ASTM D1143/D1143M-07 Standard test methods for deep foundations under static axial compressive load. American Society for Testing and Materials (ASTM), USA, 2007. $15 \mathrm{p}$.

ASTM D4945-08 Standard test method for high-strain dynamic testing of piles. American Society for Testing and Materials (ASTM), USA, 2008. $10 \mathrm{p}$.

ASTM D7383-10 Standard test methods for axial compressive force pulse (rapid) testing of deep foundations. American Society for Testing and Materials (ASTM), USA, 2010. $18 \mathrm{p}$.

Buehler, M. M.; Cudmani, R.; Libreros-Bertini, A.-B.; Osinov, V.; Gudehus, G. 2002. Experimental and numerical investigation of the influence of local site conditions on the ground motion during strong earthquakes in Bucharest, in International Conference on Earthquake Loss Estimation and Risk Reduction (ELE\&RR02), 24-26 October, 2002, Bucharest, Romania, 3-6.

Deeks, A. J.; Randolph, M. F. 1995. A simple model for inelastic footing response to, International Journal for Numerical and Analytical Methods 109(5): 307-329. http://dx.doi.org/10.1002/nag.1610190502

El-Naggar, M.; Novak, M. 1994. Non-linear model for dynamic axial pile response, Journal of Geotechnical Engineering 120(2): 308-329. http://dx.doi.org/10.1061/(ASCE)07339410(1994)120:2(308)

Gabrielaitis, L.; Papinigis, V.; Žaržojus, G. 2013. Estimation of settlements of bored piles foundation, Procedia Engineering 57: 287-293. http://dx.doi.org/10.1016/j.proeng.2013.04.039

Gholampour, A.; Ghassemieh, M. 2012. New practical approach to nonlinear dynamic analysis of structures: refinement of Newmark's and Wilson's classical methods, Practice Periodical on Structural Design and Construction ASCE 17(1): 30-34. http://dx.doi.org/10.1061/(ASCE)SC.1943-5576.0000101

Holeyman, A. E. 1985. Dynamic non-linear skin friction of piles, in International Symposium on Penetrability and Driveability of Piles, 1985, San Francisco, USA, 1: 173-176.

Holeyman, A. E. 1988. Modeling of dynamic behavior at the pile base, in The 3rd International Conference on the Application of Stress-Wave Theory to Piles, 1988, Vancouver, Canada, 174-185.

Igoe, D.; Gavin, K.; O'Kelly, B. 2010. Field tests using an instrumented model pipe pile in sand, in Proc. of the Seventh International Conference on Physical Modelling in Geotechnics, 2010, Zurich, Switzerland, 775-780.
Ishibashi, I.; Zhang, X. 1993. Unified dynamic shear moduli and damping ratios, Soils and Foundations 33(1): 182191. http://dx.doi.org/10.3208/sandf1972.33.182

Kondner, R. 1963. Hyperbolic stress-strain response: cohesive soil, Journal of Soil Mechanics and Foundations Division 89(1): 115-144.

Lysmer, J. F. E. R. 1966. Dynamic response of footing to vertical loading, Journal of Soil Mechanics and Foundations Division 92(1): 65-91.

Michaelides, O.; Gazetas, G.; Bouckovalas, G.; Chrysikou, E. 1998a. Approximate non-linear dynamic axial response of piles, Géotechnique 48(1): 33-53. http://dx.doi.org/10.1680/geot.1998.48.1.33

Michaelides, O.; Bouckovalas, G.; Gazetas, G. 1998b. Nonlinear soil properties and impedances for axially vibrating pile elements, Soils and Foundations 38: 129-142. http://dx.doi.org/10.3208/sandf.38.3_129

Middendorp, P.; Verbeek, G. E. H. 2012. At the cutting edge of pile driving and pile testing, in The $9^{\text {th }}$ International Conference on Testing and Design Methods for deep Foundations, 2012, Kanazawa, Japan, 1-7.

Nguyen, T. T. 1988. A new soil model for pile driving and driveability analysis, in The Third International Conference on Application of Stress Wave Theory to Piles, 1988, Vancouver, Canada, 353-367.

Novak, M.; Aboul-Ella, F.; Nogami, T. 1978. Dynamic soil reactions for plane strain case, Journal of the Engineering Mechanics Division 104(4): 953-959.

O’Neill, M.; Vipulanandan, C.; Wong, D. 1990. Laboratory modeling of vibro-driven piles, Journal of Geotechnical Engineering 116(8): 1190-1209. http://dx.doi.org/10. 1061/(ASCE)0733-9410(1990)116:8 (1190)

Randolph, M. F. 2003. Science and empiricism in pile foundation design, Geotechnique 54(1):143-147.

Randolph, M. F.; Simons, H. A. 1986. An improved soil model for one dimensional pile driving analysis, in The $3^{\text {rd }}$ International Conference of Numerical Methods in Offshore Piling, 1986, Nantes, France, 3-17.

Randolph, M. F.; Wroth, C. P. 1978. Analysis of deformation of vertically loaded piles, Journal of the Geotechnical Engineering Division 104(12): 1465-1488.

Sahajda, K. 2011. Calculation of piles based on CPT results in Poland, Studia Geotechnica at Mechanica 33(2): 77-86.

Shooshpasha, I.; Hasanzadeh, A.; Taghavi, A. 2013. Prediction of the axial bearing capacity of piles by SPT-based and numerical design methods, International Journal of GEOMATE 4(2): 560-564.

Smith, E. 1960. Pile-driving analysis by the wave equation, American Society of Civil Engineering Transactions 127: 35-61.

Tsai, P.; Feng, Z.; Lin, S. 2011. A wavelet based method for estimating the damping ratio in statnamic pile load tests, Computers and Geotechnics 38(2): 205-216. http://dx.doi.org/10.1016/j.compgeo.2010.11.007

Žaržojus, G.; Kelevišius, K.; Amšiejus, J. 2013. Energy transfer measuring in dynamic probing test in layered geological strata, Procedia Engineering 57: 1302-1308. http://dx.doi.org/10.1016/j.proeng.2013.04.164 
Kęstutis KELEVIŠIUS. PhD student at the Department of Geotechnical Engineering, Vilnius Gediminas Technical University (VGTU), Lithuania. Research interests include bearing capacity of vibratory piles, dynamic tests, soil - structure interaction, foundation engineering.

Linas GABRIELAITIS. Dr, Assoc. Prof. at the Department of Geotechnical Engineering, Vilnius Gediminas Technical University (VGTU), Lithuania. Research interests include computer design, foundation engineering.

Jonas AMŠIEJUS. Dr, Assoc. Prof. at the Department of Geotechnical Engineering, Vilnius Gediminas Technical University (VGTU), Lithuania. Research interests: mechanical properties of soil, determination of load intensity and deformations in strata.

Arnoldas NORKUS. Dr, Prof., Head of the Department of Geotechnical Engineering, Vilnius Gediminas Technical University (VGTU), Lithuania. Research interests: soil mechanics, modelling mechanical properties of soil, foundation and construction design.

Zbigniew SIKORA. Dr, Prof. Hab., Head of Department for Geotechnics, Geology \& Marine Engineering, Gdansk University of Technology, Poland. Research interests: soil mechanics, modelling mechanical properties of soil, advanced finite element analysis. 